\title{
Shopping, Gambling or Shambling? Penny Auctions
}

\author{
Stacey G. Robinson, East Carolina University \\ Michael D. Giebelhausen, Cornell University \\ June Cotte, Western University
}

\begin{abstract}
On penny auction websites, consumers participate in a game where the winner receives the opportunity to purchase a product for pennies on the dollar and discounts of over 90\% are often advertised and recorded. Losers, on the other hand, may easily spend hundreds of dollars and walk away with nothing. For penny auction websites, profit margins over $300 \%$ on a single auction are not uncommon. Critics call penny auctions gambling. Proponents call penny auctions entertainment shopping. Either way, this emerging form of ecommerce represents a fascinating area for academic research.
\end{abstract}

\section{Introduction}

"They are a combination of bingo night, the Home Shopping Network and a slot machine addiction (Dubois, 2010)."

Did you know a consumer can buy a new Apple iPad for only \$27 (the product typically sells for $\$ 700)$ and yet the retailer can still earn $\$ 2000$ ? How is this possible? An emerging type of e-commerce has captured the attention of consumers, investors, and regulators; however, consumer researchers have yet to explore this engaging new consumption phenomenon. Penny auctions, described as entertainment shopping by the industry, and like a drug or addiction by the popular press, sell everything from cash to luxury handbags, and vacations to laptops. If you have not heard of penny auctions, you likely will, as online and television advertising becomes more pervasive and both consumer awareness and participation increase.

Penny auctions differ from traditional online auctions (e.g., eBay) in that consumers pay to bid, with the vast majority of bidders walking away without a product and with a monetary loss. In addition, the item up for bid is sold by the penny auction website itself, as opposed to another consumer, or the manufacturer. While penny auctions have been referred to as discount shopping and games of skill, they 
have also been compared with slot machines, or other forms of gambling, as the auctions have one winner and many losers (Luscombe, 2010; Pennells, 2008; Thaler, 2009).

First appearing online in 2005, penny auctions have grown from a single auction website to more than 150 penny auction websites attracting millions of users (Pennells, 2008; The Economist, 2009). Some penny auction websites attract millions of dollars in investment capital, but still, barriers to entry are relatively nonexistent (Stone, 2010). Essentially, anyone with a computer can establish a penny auction website, as website building software is readily available, relatively inexpensive and no licensing or credentials are needed (Pennyauctionwatch.com, 2010; The Economist, 2009). The industry has a global reach and has gone largely ungoverned, a point of contention for some consumers and consumer watch groups (Kyodo News, 2010; Pennells, 2008; Pennyauctionwatch.com, 2010; The Economist, 2009).

The primary objectives of this article are to provide the academic research community with an introduction to this new phenomenon, and to begin a discussion regarding areas for fruitful research in this growing and compelling industry. As befits this special issue, this new phenomenon is conceptualized as a combination of shopping and gambling; thus shambling is at an interesting conjunction of two consumer research areas. This work broadly outlines the area, highlighting compelling and perplexing research issues and concludes with an exhortation to fellow researchers to delve into study of this fascinating phenomenon. But first, the phenomenon needs explaining.

\section{Background}

\section{How Penny Auctions Work}

Penny auction bidders pay to and per bid, and while auctions open with a predetermined end date/time, additional time is added to the auction each time a bid is placed. As a result, penny auctions may remain in their final seconds for literally hours and days (Thaler, 2009). For example, a consumer looking to purchase a new purse might decide to try her hand at one of the many penny auctions websites online. First, she purchases a bid pack of 100 bids, costing $\$ 100$. The purse she opts to bid on retails for $\$ 1200$ and the bidding starts at $\$ .01$. She bids on the purse, along with a number of competing bidders, and interestingly enough, every time someone bids on the product the time of the auction is extended, thus prolonging the final auction-end time, allowing more bidders to join the auction and bid on the item.

The consumer uses all of her bids and unfortunately, is not the final bidder. The final price of the purse is $\$ 57.36$, which seems like a real bargain for the winning bidder, but the unsuccessful bidder/ 
consumer in this scenario spent $\$ 100$ and has nothing, while the penny auction site brought in $\$ 5793$, a profit margin of $383 \%$ over retail price. This is not an uncommon scenario, and though some variation among penny auctions exists, with some bids costing less than $\$ 1$ and some auctions increasing by $\$ .02$ per bid, the process is relatively uniform and profit margins can be sizable.

\section{Why They Work - The Attraction}

Penny auction advertisements focus on deep discounts and the possibility of getting an incredible deal seemingly appeals to consumers (The Economist, 2009). Commonly, high equity brands with exclusive or limited distribution strategies and prestige pricing policies, are advertised at $90 \%$ off retail prices (see Fig. 1). In addition to offering deeply discounted goods, penny auction website operators purport consumers view penny auctions as a leisure activity, a form of entertainment shopping or game (Thaler, 2009). The combination of getting an abnormally good deal may be seen as winning, with the attendant thrill or entertainment value of that win providing the allure needed to attract consumers. One penny auction website has 2.5 million registered members (The Economist, 2009); clearly some value is conveyed by the experience.

Lucrative profit margins and relative ease of entry into the market may explain the allure for penny auction website operators and why the number of penny auction websites increased $15,000 \%$ in less than five years. The following depicts the income generated by a high equity product often featured in penny auction advertisements (see Fig. 2 and Table 1). Profit margins of 163\% are certainly atypical in traditional retail environments, but are frequently observed in the penny auction industry; indeed, margins are often much greater than this example.

\section{A Framework for Potential Research Questions}

Is this Shopping or Gambling?

Whether or not penny auctions are a new form of gambling is debatable (Gimein, 2009; Pennells, 2008). The penny auction model is similar to the dollar auction game invented by game theory pioneer Martin Shubik (Shubik, 1971; Thaler, 2009). This model relies upon escalation of commitment; people feel invested in the game once they have paid to bid on an item and have a difficult time ending play given their reluctance to walk away from their sunk costs. The concept of escalation, coupled with seemingly amazing bargain prices, such as an Apple iPad that retails for $\$ 699$ selling for $\$ 18.07$ or being advertised at $90 \%$ off, creates an environment that has been called "devilish," "addictive," 
"competitive," and "reckless" (Gimein, 2009; Luscombe, 2010; Thaler, 2009). While few consumers would likely use such adjectives to describe a typical shopping experience, such words have been used to describe a gambling experience (Cotte, 1997). While industry insiders refer to penny auctions as games of skill, gambling experts disagree, "...bidding on penny auction sites is akin to a gambling-like experience... when people bid again and again and again and don't win the item, that's very much like gambling" (Mark Griffiths, quoted in Pennells, 2008).

The debate as to whether or not penny auctions are simply a form of unregulated gambling rages on. This is perhaps the most fruitful avenue for business researchers to explore. Based upon consumer commentary on penny auction user forums, bidders who have experienced success consider penny auctions to be games of skill, and those who have lost consider them to be games of chance. Many penny auctions bear a striking resemblance to gambling, a contest where few win, many more lose, and the house always seems to profit the most (Thaler, 2009). The resemblance is particularly striking in auctions where participants wager previously purchased bids in an effort to win more bids.

On the other hand, some auctions are incorporating a buy-it-now option. This option allows consumers to apply lost bids towards purchase of the product at the listed retail price and arguably reduces the risk. To the extent that penny auctions are a form of gambling, an equal degree of regulatory oversight should be applied. Alternatively, perhaps regulation should be passed that simply restricts penny auctions to a more benign format. But social science researchers know very little about this phenomenon; regulators will be better informed if researchers begin to study this in earnest.

For gambling researchers, penny auctions present an interesting challenge. They force the question "what is gambling?" Penny auctions in which consumers bid for cash appear to cross the "entertainment shopping" line. On the other hand, auction websites which allow losing bidders to apply the cash value of their spent bids towards an outright product purchase seem much more benign. Perhaps penny auctions represent a missing link in the study of how gaming evolves into gambling.

If penny auctions are indeed gambling, as many commentators insist, then likely some small percentage of consumers encounter problematic and addictive issues with penny auctions. Some evidence of behaviors resembling gambling addiction does exist. On pennyactionwatch.com, a popular thread is titled "You Know You're a Penny Auction Bidder If." Entries in this thread include: "The only way to eat is having food delivered right to your computer desk," "You buy a bigger monitor with a gift card you won, so you can split the screen and have more auctions open at the same time," "You are willing to give up family game night just to win another game for them to play," "You vow you're going to quit this penny auction thing...as soon as you use up the last of your bids. Then proceed to buy 
another bid pack the next day...then vow to quit the day after..."This preliminary exploration clarifies that some penny auction bidders present the symptoms of addiction.

\section{What are the Managerial Implications for Brand-Name Products?}

Penny auction bargains have implications for both retailers and brands. Whereas discount retailers use price as a primary basis of comparison (Jia, 2008), high equity brands frequently use price as a way to signal quality and exclusivity (Rao \& Monroe, 1989). Given that a number of penny auction advertisements use high equity and luxury brands at ridiculously low prices as a type of bait, the retailers and managers of the brands sold by penny auctions should seek to understand the effects of unbelievable prices on consumer attitudes and perceptions toward the brand. In addition, the potential for negative affect to be associated with a particular brand, when a consumer pays to bid and loses an auction, may impact or derail brand messaging.

For marketing researchers studying branding, penny auctions present an environment in which brands have lost control over how their products are distributed, priced and to some extent, promoted. Penny auction websites often have no contractual relationship with the companies whose products are sold, penny auction operators purchase items at retail and therefore have virtually unrestricted access to any product. After all, profits are generated by numerous competing bidders who lose and receive nothing, as opposed to retail price margins. Ultra-luxury products are sold by cartoon-like branded websites, which begs the question: does a \$1500 handbag from Louis Vuitton carry the same caché when other consumers wonder if its owner paid only $\$ 15$ ? Alternatively, might a public display of people fighting over these brands simply reinforce their perceived desirability?

\section{What is the Effect on Consumer Behavior when Customers are Competitors?}

Competition among consumers has had modest mention within the literature. In general, competition and competitiveness are terms used almost exclusively to describe a business to business environment, an organizational culture, or salesperson trait (see Brown, Cron, \& Slocum, 1998). However, penny auction website profitability is largely dependent on consumer competitiveness, as bidder competition maximizes profits. Penny auction operators appear to understand this concept well. For example, penny auction website Centwar.com's tagline is "bid or be beaten," (see Fig. 3), its bids are named "ammo", and the website looks like a military operation with camouflage and war-related graphics (e.g., hand grenades). 

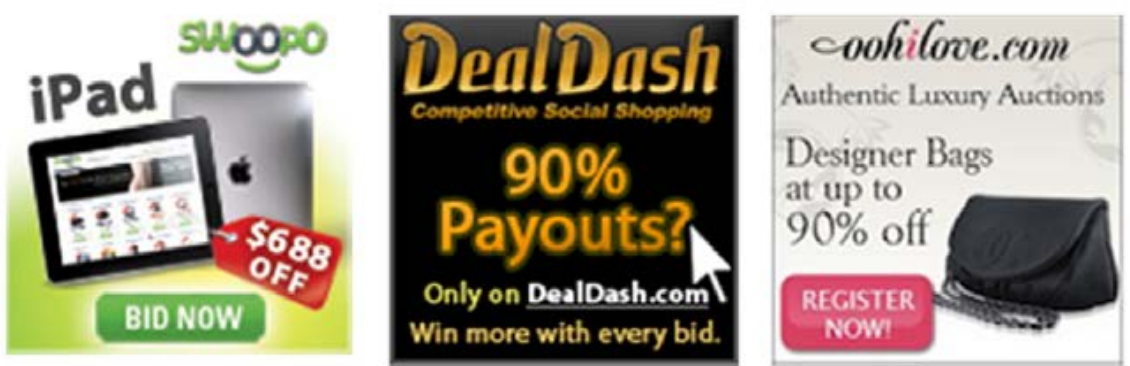

Fig. 1. Image of penny auction advertisements.
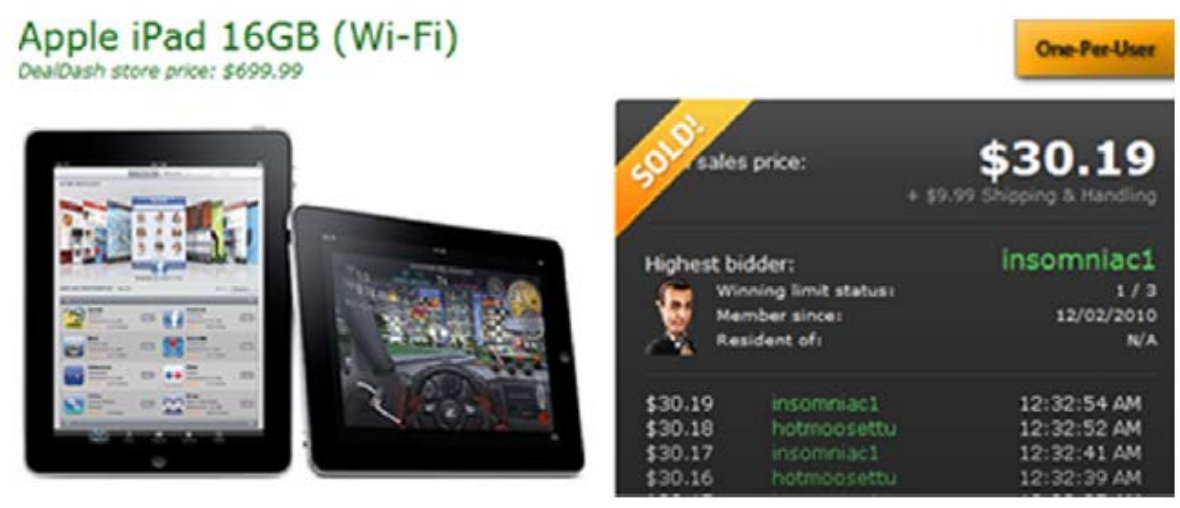

Fig. 2. Image of an Apple iPad closing price.

Similarly, penny auction consumers may view penny auctions as a competitive environment given that many choose user names that sound competitive or intimidating. For example, aggressive names such as grrrrrr, withoutlimits, gimmethis, notgonnaquit, trytokeepup, neverstopping, and nevasurrenda are commonplace on penny auctions websites. The effect such posturing has on the consumer's resolve, willingness to pay or other bidders would be an interesting area of study.

Table 1

Penny auction revenue calculation example.

\begin{tabular}{lllll}
\hline Item & Auction price & Retail price & Revenue & Profit margin \\
\hline Apple iPad & 30.19 & 699.00 & 1841.59 & $163 \%$ \\
\hline
\end{tabular}

Example from DealDash.com; revenue figure includes auction price and bid price of .60 ; profit margin assumes seller paid manufacturer retail for item.

For the ethnographer, penny auction discussion boards reveal a fascinating sub-culture complete with established hierarchies and complex social norms. The hierarchy includes "newbies" who blunder into auctions at inappropriate, though tactically superior, times and are chastised as "jumpers," and power bidders who lock horns in contests for alpha dog status (Pennyauctionwatch.com, 2010). Bidders trade tips on which penny auctions websites are the most reputable, as well as share strategies 
while simultaneously decrying players who collude during auctions. Penny auctions are a fascinating domain full of contradictions that appear to distill the relationship between human cooperation and competition.

\section{What are the Public Policy Implications?}

For those interested in public policy, penny auctions provide a fascinating case study. How can governmental agencies regulate a business model that evolves so rapidly in diverse forms? Should penny auctions be regulated? Buyers think they should and perhaps surprisingly, so do several penny auction website owners (Pennyauctionwatch.com, 2010). The question of who should regulate penny auctions seems unclear. Yet, the penny auction industry and consumers may benefit greatly from regulation. Penny auctions appear to be an ideal medium for shams given the lack of regulatory oversight and ease of entry. The rate at which new, and increasingly outlandish, adaptations of the basic penny auction business model appear is startling. Not all penny auction websites are legitimate; instances of penny auction fraud exist (Better Business Bureau, 2010). For consumers, knowing which sites to trust is difficult. For legitimate penny auction websites, fraudulent penny auctions are bad for business. Even when an auction is legitimate, consumers unfamiliar with this unusual bidding system are often surprised and angered when they spend money and walk away with nothing.

Penny auction blogs are full of cautionary tales of consumers who rack up substantial credit card debt in the unyielding pursuit of a bargain, an addictive activity labeled by the popular press as "pure heroin" and the "crack cocaine" of shopping (Gimein, 2009; Luscombe, 2010). Many potentially addictive substances and behaviors are regulated in an attempt to reduce harm. In particular, gambling laws are specifically designed to protect individuals classified as problem or addicted gamblers (Cotte \& LaTour, 2011), which leads one to ask the question, should penny auctions be regulated? How would, or could, such regulation work on the Internet?

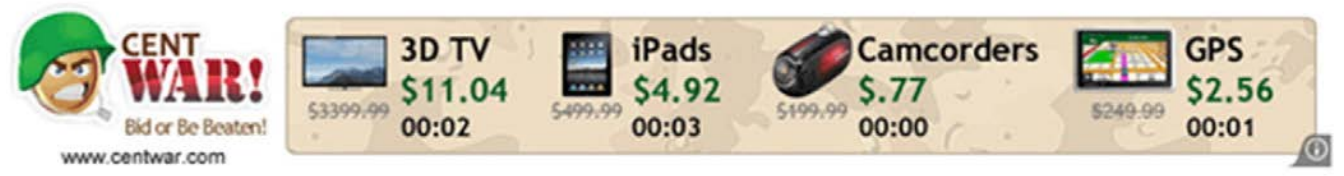

Fig. 3. This image provides an example of Centwar.com's graphics and tagline.

Internet Fraud, Illegal Behavior, and Penny Auctions

The dynamics of penny auctions provide an ideal tool for online fraud. One type of fraud entails new penny auction websites failing to deliver products after collecting bidding fees 
(Pennyauctionwatch.com, 2010). Moreover, fraudulent penny auction websites can actually benefit from their newcomer status. As established penny auctions gain credibility, they also gain power bidders who appear to monopolize the auctions; other bidders have less chance to win. Perhaps in an effort to spend less money bidding and increase their chances of winning, consumers migrate to new penny auction websites. Fraud related to non-delivery of the product is likely compounded by the penny auction business model, in that only the winning bidder will ever know the auction was fraudulent. Additionally, in some fraudulent auctions, no winner emerges due to shill bidding. Shill bidding is an activity in which the penny auction website bids on its own auctions to drive up the price or prevent a consumer from winning, thus alleviating the need to deliver an actual product (Kyodo News, 2010). In a traditional auction setting, this activity poses some risk to the seller, given that the shill bid may be the highest bid and the product will not sell.

But with penny auctions, the most profitable short-term strategy would be for the website to win all of its own auctions and deliver zero products, given that profits are derived from those paying to bid as opposed to the final, pennies on the dollar, auction price. Interestingly, some penny auction software packages are designed to allow sellers to shill bid. This potentially fraudulent feature is marketed as an auction testing application. Watchdog groups, such as Pennyauctionwatch.com, attempt to uncover websites where shill bidding occurs. However, given the likely allegiance of software developers to penny auction site owners, one might suspect well intentioned watchdog groups are fighting a losing battle.

A number of penny auction websites with activities closely resembling illegal business models exist. New to the scene is a penny auction website that resells tickets to concerts and other ticketed events. While various laws govern maximum profits on ticket resale, in order to limit ticket scalping, the question of how these laws should be applied to tickets sold in a penny auction setting is interesting, given one winner, multiple losers and sizeable profit margins. Another business model entails a penny auction website which offers winning bidders the opportunity to resell their win, as opposed to taking physical possession of the item, and split the profits with the penny auction site owners. 


\section{Predict Final Price \& Win!}

\section{Right prediction wins you:}

\section{FREE BIDS}

It costs 10 bids to make a prediction. Please login to make a prediction

Fig. 4. This image promotes a prediction game option at BidHere.com.

Theoretically, such a model could function without ever delivering any products. This model closely resembles a pyramid or Ponzi scheme and is illegal in many countries. Other potentially worrisome innovations include: auctions that encourage bidders to wager on the closing price of an individual auction, an outcome they may be able to partially control, in exchange for additional bids (e.g., predict the final auction price for 10 bids and win 100 bids) (see Fig. 4), mystery auctions where the product and its value are unknown until won, and win-or lose- everything auctions in which the losers lose every bid in their account if they are not the winning bidder - effectively forcing individuals to bid it all.

\section{Government Regulation and Taxation}

The Unlawful Internet Gambling Enforcement Act of 2006 (UIGEA; 31 U.S.S. §§ 5361-5367) was written in an attempt to inhibit online gambling. The act prohibits U.S. based financial institutions from handling internet gambling-related transactions. While internet gambling, within the US, is not illegal, banks may not legally handle any monies related to such activity. However, legislation to repeal the UIGEA is being considered as individual states entertain both the legalization and taxation of online gambling (Siemens \& Kopp, 2011). The impetus of such activity is likely related to forgone revenue. For example, the state of Kentucky taxes individual income earned via online horse racing betting (Cypra, 2010).

The question of whether or not penny auctions should be subject to public regulation and taxation looms and the answer to this question lies primarily in defining penny auctions. If penny auctions are classifiable as an alternate form of internet retailing, then government oversight does not require expansion or modification, as policy governing retailers exists. However, if penny auctions are a type of lottery or online gambling, government regulation and policy would require reform to make 
accommodations for this new form of commerce at both federal and state levels. Again, answering the question of whether this activity is shopping or gambling is important to effective public policy.

\section{Conclusion}

No longer a theoretical curiosity for game theory economists, penny auctions are multiplying and mutating at an exponential rate in the real world. The study here introduces academic researchers to this puzzling, though increasingly popular phenomenon. Penny auctions, while fascinating in their own right, offer a unique vantage from which one can examine a wide variety of research domains. Business researchers may wish to apply the lenses of behavioral economics, psychology, and anthropology to this challenging new consumer phenomenon as the many unanswered questions herein, have far-reaching implications.

\section{References}

Brown, S. P., Cron, W. L., \& Slocum, J. W., Jr. (1998). Effects of trait competitiveness and perceived intraorganizational competition on salesperson goal setting and performance. Journal of Marketing, 88-98.

Better Business Bureau (October 1). Be cautious of online penny auction sites. retrieved January 27, 2011 from http://www.bbb.org/us/article/be-cautious-of-online-penny- auction-sites-22506

Cotte, J. (1997). Chances, trances and lots of slots: Gambling motives and consumption experiences. Journal of Leisure Research, 29(4), 380-406.

Cotte, J., \& LaTour, K. (2011). Gambling myths vs. reality: Implications for transformative public policy. In D. G. Mick, S. Pettigrew, C. Pechmann, \& J. Ozanne (Eds.), Transformative consumer research for personal and collective well-being (485-498). New York, NY: Routledge.

Cypra, D. (2010, February 28). Kentucky house passes bill taxing online and phone horse racing wagers. Poker News, retrieved January 23, 2012 from http://www.pokernewsdaily. com/kentuckyhouse-passes-bill-taxing-online-and-phone-horse-racing-wagers-8634/

Dubois, S. (2010, January 21). Penny auctions bet on chump change. Wired, retrieved January 28, 2011 from http://www.wired.com/business/2010/01/penny-auctions- bet-on-chump-change-part-iof-ii/

Gimein, M. (2009, July 7). The crack cocaine of auction sites. The Big Money, retrieved January 27, 2011 from http://www.thebigmoney.com/print/2745 
Jia, P. (2008). What happens when Wal-Mart comes to town: An empirical analysis of the discount retailing industry. Econometrica, 76(6), 1263-1316.

Luscombe, B. (2010, June 17). Losing your cents. Time, retrieved January 27, 2011 from http://www.time.com/time/printout/0,8816,1997462,00.html

Kyodo News. (2010). Complaints against new type of internet auction growing. (2010, December 28). Kyodo News, retrieved January 28, 2011 from http://english.kyodonews. $\mathrm{jp} /$ news/2010/12/63977.html

Pennells, S. (Reporter). (2008, December 20). BBC, Questions over web auction sites (Television broadcast).

Pennyauctionwatch.com. (2010, November 20). Enough is enough. Pennyauctionwatch.com, retrieved January 27, 2011 from http://www.pennyauctionwatch.com/2010/11/penny- auction-scamscon-artists/

Rao, A. R., \& Monroe, K. B. (1989). The effect of price, brand name, and store name on buyers' perceptions of product quality: An integrated review. Journal of Marketing Research, 26(8), 351-357.

Shubik, M. (1971). The dollar auction game: A paradox in noncooperative behavior and escalation. Journal of Conflict Resolution, 15(1), 109-111.

Siemens, J. C., \& Kopp, S. W. (2011). The influence of online gambling environments on self-control. Journal of Public Policy \& Marketing, 30(2), 279-293.

Stone, B. (2010, August 12). Penny auction sites hurt by glut of competitors. Businessweek, retrieved January 27, 2011 from http://www.businessweek.com/magazine/content/10 34/b4192040657482.htm?campaign id= rss null

Thaler, R.H. (2009, November 15). Paying a price for the thrill of the hunt. New York Times, Economic Review.

The Economist (August 15). Mind the pennies: The rapid spread of "entertainment shopping" spurs indignation. The economist (retrieved January 27, 2011 from http://www.economist.com/node/14214837/print) 